\title{
Creating and Managing EU Funded Research Networks: An Exploratory Case
}

\author{
Zeta Dooly ${ }^{1}$, Aidan Duane ${ }^{1}$ and Aidan O'Driscoll ${ }^{2}$ \\ ${ }^{1}$ Waterford Institute of Technology, Waterford City, Ireland \\ ${ }^{2}$ Dublin Institute of Technology, Ireland \\ zdooly@wit.ie \\ aduane@wit.ie \\ aidan.odriscoll@dit.ie
}

\begin{abstract}
The collaborative European funded research and development landscape drives competitiveness among innovative organisations. Recently it has seen the rise of public private partnerships significantly impacting the dynamics of these networks. Thus, the complexity of managing research networks has intensified with the increased diversity of research network members. Additionally, the emergence of the academic entrepreneur has augmented the focus of educational institutions to include innovation and building start-up organisations. The impact of research is scalable if an optimum research network is created and managed effectively. This paper investigates network embeddedness; the nature of relationships, links and nodes within a research network, specifically their structure, configuration and quality. The contribution of this paper extends our understanding for establishing and maintaining effective collaborative research networks. The effects of network embeddedness are recognized in the literature as pertinent to innovation and the economy. Network theory literature claims that networks are essential to innovative clusters such as Silicon valley and innovation in high tech industries. The concept of embeddedness is what differentiates network theory from economic theory. This study adopts a qualitative approach and uncovers some of the challenges of multi-disciplinary research through case study insights. One challenge is competition between network members over ownership and sharing of data. The contribution of this paper recommends the establishment of scaffolding to accommodate cooperation in research networks, role appointment, and addressing contextual complexities early to avoid problem cultivation. Furthermore, it suggests recommendations in relation to network formation, incubation and operations. The network capability is enhanced by the recognition of network theory, open innovation and social exchange with the understanding that the network structure has an impact on innovation and social exchange in research networks and subsequently on research output. The research concludes that the success of collaborative research is reliant upon establishing a common language and understanding between network members to realise their research objectives.
\end{abstract}

Keywords: research networks, structural embeddedness, network theory, case study.

\section{Introduction}

In 2018 the EU spent $€ 295$ billion on Research and development. This research investigates collaborative research across EU member states using a case study approach. It provides evidence in relation to setting up research networks and it presents barriers and opportunities that arise whilst conducting research across multidisciplinary teams and distinct organisations.

Over the past few decades, there has been an explosion of interest in network research across the physical and social sciences. Network theory has yielded explanations and increased understanding for social phenomena in a variety of disciplines (Borgatti et al., 2009; Moreno and Jennings, 1934). For example, Granovetter (1973) postulated that when Boston claimed to absorb two neighbouring towns it was the collective action of one town generated by its more diffuse network structure that blocked the action. Furthermore, the literature has presented evidence that indicates higher order dynamic capabilities, competencies and new service offerings as a result of network alliances (Agarwal and Selen, 2009; 2011; Gulati, 1995; 1998). However, there is little evidence within the EU funded research context, a unique landscape for networking and emergent innovation, product and service capability. Our society adopts community approaches to achieve progress across a myriad of initiatives, open source software development is one such example and collaborative research funded by the European Commission is another. This paper focusses on the latter whilst cognisant of the impact of both examples toward citizen empowerment and societal progression.

Traditional and academic entrepreneurs are working together to refine the role of educational institutions to meet market needs (Etzkowitz, 2003; Perkmann et al., 2013; Bolzani et al., 2014). This research investigates structural embeddedness which refers to the nature of relationships, links and nodes within a netoliwork, Networks: An Exploratory Case. The Electronic Journal of Business Research Methods, 20(1), pp. 1-20, available online at www.ejbrm.com 
specifically their structure, configuration and quality. Research networks provide a rich setting to analyse structural embeddedness. The effects of network embeddedness are recognized in the literature as pertinent to innovation and the economy (Gilsing et al., 2008; Owen-Smith and Powell, 2004; Rowley, Behrens and Krackhardt, 2000). The literature highlights the role of inter-personal relationships as significant. However, the governance model inadequately addresses the complexity of research networks formed in response to funding opportunities. Research networks face two important and competing challenges, protecting data confidentiality while maximizing data accessibility (Perkmann and Schildt, 2015; Mehlman et al., 2010; Melese et al., 2009). In recent research output evaluations the focus of attention is moving from output to impact which is a significant change in the area of practice (Bozeman and Melkers, 2013). This emphasis on impact is different to the traditional norms of academic behaviour where often the value of research was peer recognition within the closed research community in the form of publications and conferences. Regular liaison between academia and industry opens up the potential for the exploration of new joint research norms and behaviours.

The aim of this paper is to investigate structural embeddedness within a multi-disciplinary research network, its formation, configuration and operations. This study adopted a qualitative case study method comprising of 7 partners from 5 member states and 1 associated country. The consortium is coordinated by TSSG (Ireland), a department within Waterford Institute of Technology, who are an internationally recognized centre of excellence for ICT research and innovation. The research network includes a diverse mix of researchers, and inter-disciplinary expertise. This study provides rich insights to the operations of this networks and the complexities encountered within this context in relation to merging economics, society and technology. The research illustrates the major impact that multi-disciplinary research has had on the industry and the visionary role of the research network. This paper contributes to the literature in relation to understanding network embeddedness in depth.

This research has developed a set of practical recommendations for network formation, incubation and operations, cognisant of the role structural embeddedness plays within a research network. This study provides strong evidence to demonstrate the impact configuration and quality of inter-organisational relationships has on network operations. It is clear from the study that the depth of the relationships within the network contributed significantly to the positive collaboration, mutual respect and successful evaluation of the research. The research setting is within the complex collaborative European funded research and development landscape which has changed substantially in recent years. The European Commission places a large emphasis on its research programme to foster innovation and competitiveness through excellence in ICT research and development. The people (actors in the network) and the in-built structure of the network is critical to understanding the roles, enablers and barriers to successful research. This research shows that prior relationships are important, common ground rules need to be established and conflict is common due to the competitive nature of markets and economics.

The following sections discuss the pertinent literature followed by section 5 which details the research process and section 7 which presents the findings in relation to understanding how the structure of the network combatted the bottlenecks encountered and positively contributed to the success of the research network.

\section{Research network composition; social side of early innovators and reciprocity.}

This research leverages network theory and Research in network theory is related to graph theory and looks at asymmetric relations between discrete objects. The first proof of network theory is the Seven Bridges of Königsberg (Newman, Barabasi and Watts, 2006). Problems can be represented as a graph, and network theory provides a set of techniques for analysing graphs. In social science, network theory consists of actors (nodes) and their relations (ties) between these actors (Wasserman and Faust, 1994; Fleming and Frenken, 2007). Nodes may be individuals, groups, organizations, or societies. Wellman and Berkowitz (1988) argue that network analysis is merely a tool that facilitates the study of social structures that can detect patterns of behaviour. Network theory is well established since its inception around 1800, the associated empirical evidence from network theory is prolific. Furthermore, the recognition of network theory within social science has led to an increase in research of social network theory and social exchange theory.

Network theory literature claims that networks are essential to innovative clusters such as Silicon valley (Fleming and Frenken, 2007) and innovation in high tech industries (Owen-Smith and Powell, 2004). Network theory has many supporting examples including the diffusion of technology and innovation (Coleman et al., 1966; Strang 
and Macy, 2001). Granovetter (1985) in his work on how behaviour and institutions are affected by social relations argues that Williamson (1979) does not sufficiently consider personal relationships during economic transactions (the network effects). This critique illustrates how the transaction cost economics (TCE) theory explicitly excludes an individual's behaviour, actions or the exchange of a commodity whereas Granovetter (1985) argues that economic action is embedded in structures of social relations. It is also worth noting that Granovetter (1973) illustrates the significance of the network effect of early innovators as opposed to first adopters. For this study, research network theory is considered highly relevant; the actors (nodes) involved are academic researchers, innovators, policy administrators and industrial organisations working collaboratively toward research innovation. Network analysis focuses on these relationships and explains the attitudes and behaviours of these actors and organisational members. It is clear from the increase in the emergence of formal and informal inter-organisational cooperation such as public private partnerships, joint ventures and contractual partnerships that collaborative networks are a critical organisational activity. In addition, with communication and information exchange facilitated by Internet trends such as micro-blogging and the additional complexity involved in follower and following type activities, there is sufficient evidence to suggest on-going research interest in this domain.

Specifically research in social network theory has expanded significantly over the last decade and a succinct account of the emerging arguments and topics is included in the book "The Development of Social Network Analysis" (Freeman, 2011). Conceptual models emerging from network theory explain how social networks operate. These include; self-interest, whereby the objective is to maximize personal gain, preferences and desires (Homans, 1964); social capital, which is the collective value of social networks (Bourdieu and Wacquant, 1992; Putnam, 1993; Portes, 2000), collective action such as the building of public parks and bridges (Marwell and Oliver, 1993; Monge et al., 1998) and, social exchange and dependency (Bienenstock and Bonacich, 1997).

Research in relation to networks working together on tasks, sharing responsibility and creating new knowledge through the sharing of resources spans a number of inter-related research domains; network theory, social network theory, social exchange theory, social capital theory. (Nahapiet and Ghoshal, 1998; Burt, 2009; Granovetter, 1973; Granovetter, 1985; Bourdieu, 2011; Putnam, 1995; Coleman, 1988). Emerson (1976) asserts that social exchange theory examines the exchange (productive exchange) of all relevant ties in the appropriate networks whereas network theory examines the nature of all links without assessing relevance in advance. Of interest to this research study is the role of networks relating to the network embeddedness, reuse of networks, the development of social capital and network value analysis (Granovetter, 1973; Coleman, 1988; Burt, 2009; Wenger, Trayner and de Laat, 2011; Blau, 1964; Putnam, 1995). In line with the literature the author acknowledges the significance of weak ties in relation to opportunity and the role reputation plays in relation to the re-use of networks from one purpose to another.

It is useful to examine inter-organisational networks in research environments through a network lens, particularly the linkages between nodes (actors) and their relationships and associated activities. For the purpose of this study, social capital can be considered both the structure of the relationship networks and the resources that can be accessed through these relationships. It is the link between relationship and resource that is of particular interest to the study. Furthermore, Granovetter (1992) two dimensional inquiry (structural and relational) embeddedness illustrates that the source of competitive advantage can be linked to the history and configuration of interactions., demonstrating essential reputational aspects. This concept of embeddedness is what differentiates network theory from economic theory.

\section{Application of network theory in social science.}

Network, and particularly social network theory, is not without its critics. Mejias (2005) describes networked individualism as discriminative of the space between the nodes arguing that interests need to become nonnodal. This notion of nodes within a network unable to communicate outside of individual nodes is more challenging within network theory in social science than physical science (Borgatti et al., 2009; Vandenberghe, 2002). This will be addressed in the research method and design phase of this study. Given the temporal and spatial diversities of networks, it is feasible to test this argument but its relevance is less significant for this piece of research given its objective and context in research networks. This research explores the actors (and their relationships) involved in collaborating to research and explore elements of the societal impact (e.g. network properties and differences in impact). Figure 1 depicts a simplified network (nodes and ties). 


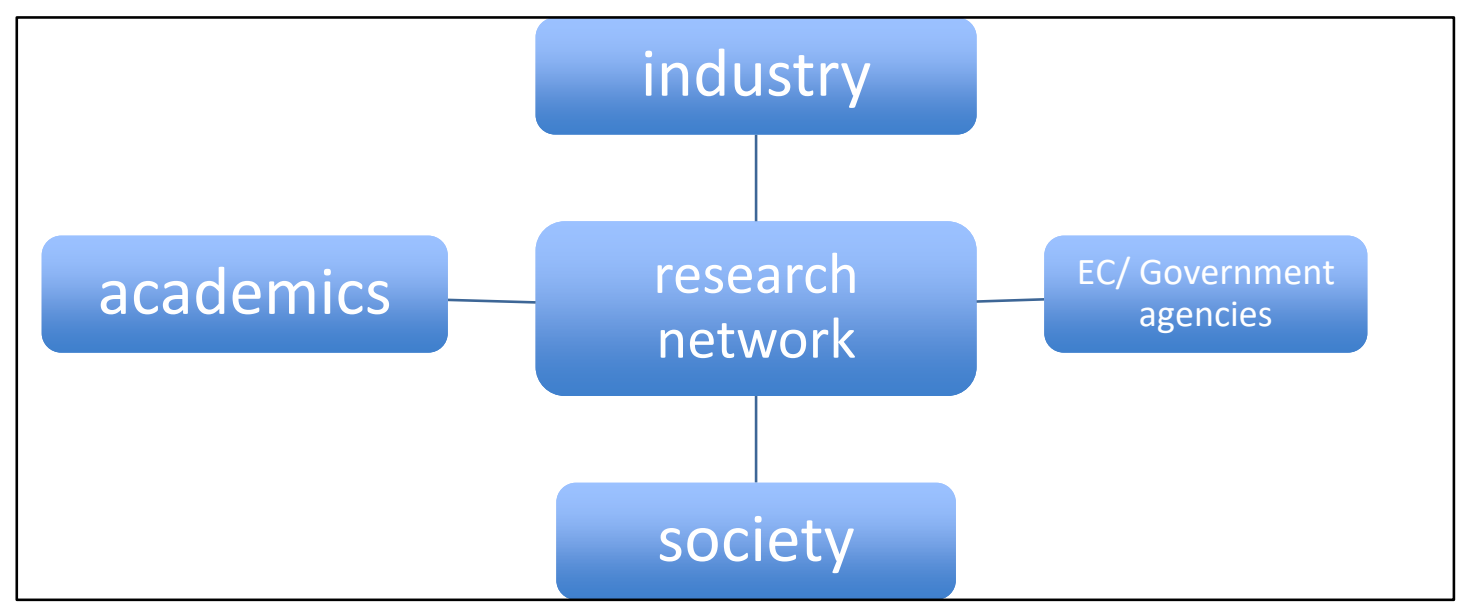

Figure 1: Network nodes

A research network enhances overall network capability, a firm's ability to develop and utilise interorganisational relationships to gain access to various resources held by others. Network capability development poses significant challenges and opportunities such as driving competitive advantage, resource constraints and recognising network capability as a resource of the firm (McGrath and O'Toole, 2014; Walter, Auer, \& Ritter, 2006). This research explores actor activity, individual characteristics and network properties toward network capability in research networks cognisant of the cultural and innovation dimensions examined in McGrath and O'Toole (2014).

Furthermore, the process of acquiring resources such as financial, physical, human, and intangible capital from others is commonly acknowledged to be a vital entrepreneurial task (Shane, 2003; Starr and MacMillan, 1990). It is generally accepted that in order for firms to gain or sustain competitive advantage, research and development (R\&D) activities are crucial to their products and services. Therefore, one can start to visualize the storyboard in relation to network capability, research management and network theory, in line with the evidence presented.

To date, much resource acquisition research has focused on two fronts by which entrepreneurs attempt to cope with the above-noted challenges: relying on social ties and signalling quality. The social tie approach emphasizes the facilitative role played by an entrepreneur's direct or indirect connections to potential capital providers (Hall and Hofer, 1993; Steier and Greenwood, 1995; 2000). This approach has been criticized, however, for failing to satisfactorily explain the processes by which entrepreneurs leverage their existing relationships to secure additional capital (Baron and Markman, 2003; Martens, Jennings and Jennings, 2007). Given the current emphasis on converting basic research to applied and commercial success, this further accentuates the importance of network embeddedness in research networks. Within the context of this study the acquisition of resources by network actors is not clearly evident in the literature as opposed to traditional perspectives of measuring research output and impact (Bozeman and Melkers, 2013; Perkmann et al., 2013). In agreement with Bozeman and Melkers (2013), it is clear that there is a gap in the literature on emergent output and the author concurs with Bozeman and Melkers that further research in the area is needed.

\section{Structural embeddedness and collaboration in research networks.}

Research networks provide a mechanism to analyse structural embeddedness. Structural embeddedness refers to the nature of relationships, links and nodes within a network, specifically their structure, configuration and quality. The effects of network embeddedness are recognized in the literature as pertinent to innovation and the economy (Gilsing et al., 2008; Owen-Smith and Powell, 2004; (Gilsing et al., 2008; Owen-Smith and Powell, 2004; Rowley, Behrens and Krackhardt, 2000). Network theory literature claims that networks are essential to innovative clusters such as Silicon Valley (Fleming and Frenken, 2007) and innovation in high tech industries (Owen-Smith and Powell, 2004). Granovetter (1985) concept of embeddedness is what differentiates network theory from economic theory. Funding competitiveness, public private partnerships (PPP), open data policies and more poignant multi-disciplinary research means that networks of people involved in funded research are fundamentally different in recent years. How these networks operate, collaborate, and acquire new knowledge and products contributes to society. Traditional and academic entrepreneurs are working together to refine the 
role of educational institutions to meet market needs (Etzkowitz, 2003; Perkmann et al., 2013; Bolzani et al., 2014).

Network theory is relevant to investigate inter-personal relationships, links and ties between the network actors. The 'valley of death' gap as coined by Maughan et al. (2013) has the potential to widen where trust and reputation are integral to open data policies and confidentiality clauses. The European Commission research governance model inadequately addresses the complexity of research networks formed in response to funding opportunities. Research networks face two important and competing challenges, protecting data confidentiality while maximizing data accessibility (Perkmann and Schildt, 2015; Mehlman et al., 2010; Melese et al., 2009). Regular liaison between academia and industry opens up the potential for the exploration of new joint research norms and behaviours. Highly competitive markets and the dynamic nature of technology-driven solutions have embedded open innovation as a success mechanism for organisations to foster growth and economic reward (Enkel, Gassmann and Chesbrough, 2009; Chesbrough, 2003; Perkmann and Walsh, 2007). However, converging partners collaborate even though they continue to pursue individual sets of beliefs, objectives and norms, with the literature highlighting the distinctions between academic and commercial motivations influencing societal and economic impacts (Melese et al., 2009; Mehlman et al., 2010).

\section{Research Methodology}

The study adopts an interpretivist frame and is not looking for a cause and effect type explanation that would be more characteristic of positivist research paradigms. Instead it aims to investigate social and economic aspects of structural embeddedness in an ICT research network based in the European Union. The philosophical positioning of this research study is relevant to understand the impact these arguments have on choosing the appropriate method for conducting the research. The adopted philosophical assumptions of the researcher have a direct impact on operational research design and method. Building upon the work of Burrell and Morgan (1979), Kilduff, Mehra and Dunn (2011) present a new wave of research assumptions contextualized in modern society along with the emergence of technical transfer, disparate philosophical groups within organisations and open innovation. This is particularly relevant in this research as it is conceivable that the research networks comprise of disparate philosophical groups. To date much of the empirical evidence presented in relation to funded research networks is quantitative, while providing excellent insights, adopting a qualitative approach has opportunity to provide deeper insights through the narrative of the active research network participants (Freeman, 2004; Freeman, 2011; Scherngell and Barber, 2011; Scherngell and Lata, 2013; Wanzenböck, Scherngell and Lata, 2015; Herz, Peters and Truschkat, 2014; Carrington et al., 2005; Scott and Carrington, 2011).

The philosophical underpinning of the adopted methodology is based on an interpretivist epistemology and a constructivist ontology given the context of the study; highlighting the need for an inductive study to investigate the research problem. A deep understanding of network embeddedness is critical to explore this domain in this context beyond the existing predominantly quantitative studies (Herz, Peters and Truschkat, 2014). Adopting an epistemological intermediary approach is appropriate for this study.

Furthermore, the case study approach is appropriate as it enables the researcher to explore an area in which few previous studies have been carried out (Perkmann and Schildt, 2015; Wanzenböck, Scherngell and Lata, 2015; Bozeman and Gaughan, 2007; Bozeman and Melkers, 2013; Cook and Whitmeyer, 1992). In Krippner et al. (2004) social and economic aspects are discussed and contributed to their inclusion in this study. Additionally, the literature on network research purports that where complexity and dynamism of relationships limit the applicability of positivist research, based on inferential methods, qualitative case study methods are preferential (Hite, 2005; McGrath and O'Toole, 2014; Krippner et al., 2004). Beckmann and Padmanabhan (2009) contend that a study of institutional and contextual influences warrants a case study approach. The case study approach provides context within which exploratory research can be conducted. It is an appropriate strategy where a contemporary phenomenon is to be studied in its natural context, and the focus is on understanding the dynamics present (Myers, 1997; Agarwal and Selen, 2009; Brown, 2015; Wenger, 2010; Wenger, Trayner and de Laat, 2011).

This research is exploratory; the data collection strategy is multi-modal and includes a single case study, qualitative semi-structured interviews and documentation analysis. The data analysis strategy focuses on iterative research analysis cycles using state of the art software and research processes. Before selecting the case study explicit criteria (Table 1) was identified to increase the feasibility of the research implementation. 
Table 1: Criteria for Organisational Participation in the Study

\begin{tabular}{|l|}
\hline \multicolumn{1}{|c|}{ Criteria for Selection of a Single Case for this Study } \\
\hline The network Coordinator has agreed to participate fully in this study \\
\hline The network Coordinator supports publication of the findings from the study \\
\hline The Coordinator of the network is located in Ireland to minimise the research costs \\
\hline The network Coordinator considers structural embeddedness in networks as important \\
\hline $\begin{array}{l}\text { The network Coordinator has granted the researcher access to project documentation, communication material and } \\
\text { research artefacts, and any other documentation deemed necessary for the study (e.g. code of ethics, project handbook } \\
\text { and reports). }\end{array}$ \\
\hline $\begin{array}{l}\text { The network Coordinator has provided the researcher with access to the network nodes for the purpose of interviewing } \\
\text { and has made the appropriate introductions }\end{array}$ \\
\hline
\end{tabular}

Natural construction of the interaction within the network is core to the conceptual framework and is best understood in its natural environment rather than through experimentation or action of the researcher. Phase 1 involved familiarisation with the data; this included multiple sources of data, and many rounds of data familiarisation, reading, sorting, summarising and making notes and memos in relation to the data. The primary data collection was during the semi-structured interviews. The research participants Table 2 provides details of the interviews including the format and timing.

Table 2: Research Participants

\begin{tabular}{|c|c|c|c|c|c|c|}
\hline $\begin{array}{l}\text { Cod } \\
\text { e }\end{array}$ & $\begin{array}{l}\text { Participant } \\
\text { Title }\end{array}$ & Organisation & $\begin{array}{l}\text { Interview } \\
\text { Completed }\end{array}$ & $\begin{array}{l}\text { Intervie } \\
\text { w } \\
\text { Format }\end{array}$ & $\begin{array}{l}\text { Intervie } \\
\mathbf{w} \\
\text { Duration }\end{array}$ & $\begin{array}{l}\text { Associated } \\
\text { Documentation }\end{array}$ \\
\hline$A$ & $\begin{array}{l}\text { Project } \\
\text { Coordinator }\end{array}$ & TSSG/WIT & $30 / 08 / 2017$ & In Person & 1.04 & $\begin{array}{l}\text { Project Brochure } \\
\text { Project Plan }\end{array}$ \\
\hline B & $\begin{array}{l}\text { CEO i2S - } \\
\text { Business } \\
\text { Development } \\
\text { Manager }\end{array}$ & $\mathrm{i} 2 \mathrm{~S}$ & $21 / 08 / 2017$ & Skype & 0.50 & Website Blog Articles \\
\hline $\mathrm{C}$ & $\begin{array}{l}\text { Researcher at } \\
\text { UNINOVA }\end{array}$ & UNINOVA & $27 / 07 / 2017$ & Skype & 0.50 & Website Blog Articles \\
\hline $\mathrm{D}$ & $\begin{array}{l}\text { Technical } \\
\text { Manager }\end{array}$ & Andromeda & $17 / 08 / 2017$ & Skype & 0.54 & \\
\hline$E$ & $\begin{array}{l}\text { Marketing and } \\
\text { Business } \\
\text { Development } \\
\text { Manager }\end{array}$ & Grammos & $03 / 08 / 2017$ & Skype & 1.02 & \\
\hline$F$ & $\begin{array}{l}\text { Fish Farm } \\
\text { Manager }\end{array}$ & Ardag & $02 / 10 / 2017$ & Skype & 0.53 & \\
\hline $\bar{G}$ & $\begin{array}{l}\text { Managing } \\
\text { Director }\end{array}$ & Q-Validus & $11 / 10 / 2017$ & Phone & 0.55 & $\begin{array}{l}\text { CEN Standards } \\
\text { Workshop Report }\end{array}$ \\
\hline $\mathrm{H}$ & $\begin{array}{l}\text { Software } \\
\text { Engineer and } \\
\text { Computer } \\
\text { Consultant }\end{array}$ & $\begin{array}{l}\text { Institute "Jozef } \\
\text { Stefan" }\end{array}$ & $19 / 10 / 2017$ & Skype & 0.59 & \\
\hline 1 & $\begin{array}{l}\text { Innovation } \\
\text { and Business } \\
\text { Development } \\
\text { Manager }\end{array}$ & Q-Validus & $13 / 10 / 2017$ & In Person & 1.18 & $\begin{array}{l}\text { Dissemination } \\
\text { Materials } \\
\text { D5.6, D5.7, D5.8 } \\
\text { Web Blog Articles, } \\
\text { Website }\end{array}$ \\
\hline $\mathrm{J}$ & Technical lead & TSSG/WIT & $29 / 09 / 2017$ & In Person & 1.26 & $\begin{array}{l}\text { Industrial and Business } \\
\text { Report }\end{array}$ \\
\hline
\end{tabular}

During the data collection phase, the participants provided profile information, which gave a descriptive background for the case study and the individuals (network nodes). There were a number of different roles identified within the case study (Figure 1) and the collected data provides some descriptive data in relation to these roles and related attributes identified. The source of this data was the individual participants organisation profile questionnaire; this was requested during the interviews and followed-up by email communications. The majority (70\%) of participants were ICT focussed with $30 \%$ from industry. The participant gender was predominately male $90 \%$, and the organisation sizes varied. The participants were highly experienced with $70 \%$ 
having more than 10 years-experience in their field. The funding of the participants was divided evenly with $50 \%$ privately funded and $50 \%$ publicly funded.

Table 3: Individual and Organisation Attributes for Case Study

\begin{tabular}{|l|l|l|l|l|l|l|l|}
\hline $\begin{array}{l}\text { Stakeholder } \\
\text { Type }\end{array}$ & $\begin{array}{l}\text { Industry } \\
\text { Focus }\end{array}$ & Gender & $\begin{array}{l}\text { Organisation } \\
\text { Size }\end{array}$ & Role & $\begin{array}{l}\text { Years } \\
\text { Experience }\end{array}$ & Funding & Location \\
\hline Industry & Non-ICT & Male & Medium & $\begin{array}{l}\text { Aquaculture } \\
\text { Expert }\end{array}$ & Unassigned & Private & Spain \\
\hline Academic & ICT & Male & Small & $\begin{array}{l}\text { Software } \\
\text { Engineer }\end{array}$ & $>10$ years & Public & Portugal \\
\hline Industry & ICT & Male & Micro & $\begin{array}{l}\text { Project } \\
\text { Manager }\end{array}$ & $>10$ years & Public & Ireland \\
\hline Academic & ICT & Male & Small & $\begin{array}{l}\text { Project } \\
\text { Manager }\end{array}$ & $>10$ years & Public & Ireland \\
\hline Academic & ICT & Male & Large & $\begin{array}{l}\text { Software } \\
\text { Engineer }\end{array}$ & $>10$ years & Public & Ireland \\
\hline Industry & ICT & Male & Small & $\begin{array}{l}\text { Software } \\
\text { Engineer }\end{array}$ & $>10$ years & Private & Greece \\
\hline Academic & ICT & Male & Large & $\begin{array}{l}\text { Software } \\
\text { Engineer }\end{array}$ & $<10$ years & Public & Slovenia \\
\hline Industry & Non-ICT & Male & Medium & $\begin{array}{l}\text { Aquaculture } \\
\text { Expert }\end{array}$ & $<10$ years & Private & Israel \\
\hline Industry & ICT & Male & Micro & $\begin{array}{l}\text { Project } \\
\text { Manager }\end{array}$ & $>10$ years & Private & Ireland \\
\hline Industry & Non-ICT & Female & Small & $\begin{array}{l}\text { Aquaculture } \\
\text { Expert }\end{array}$ & $<10$ years & Private & Greece \\
\hline
\end{tabular}

The case study included eight organisation partners in the AquaSmart network. There were ten participants interviewed and $70 \%$ of participants had greater than ten years' experience in their domain. The network included 3 academic partners, 3 end-user partners and 2 ICT partners. The data collection phase was seven months in duration between July 2017 and January 2018. This included formal requests for participation, scheduling, preparation of the participant guide, conducting the semi-structured interviews, documentation analysis and reflective writing. A purposive sampling strategy of 10-targeted researchers was chosen. This nonprobability sampling technique leverages the experience and judgement of the researcher.

The unit of analysis is the individual in the network (network node). In accordance with best practice the researcher investigated all network nodes within the network. This helped to gain insights from each member of the network rather than dilute the investigation to a portion of the network, and is considered a crucial research design choice. Furthermore, the researcher analysed archival data, which is common in this domain as evidenced by studies by Greer and Lei (2012); Geisler (2003); Kirschner et al. (2004); Perkmann and Schildt (2015).

The initial research design adopted an iterative approach for data analysis and was guided by Tracy (2013) and Miles and Huberman (1994). However, upon implementation, the model developed by Braun and Clarke (2006) employed as a more comprehensive guide. To identify convergence of themes and patterns across interviews, the data and literature was iteratively examined with initial codes or themes developed based on a pattern between the data and the conceptual framework in line with literature and a priori themes (Hite, 2005; McGrath and O'Toole, 2014; Miles and Huberman, 1994; Yin, 2003).

The Braun and Clarke (2006) inductive research model that was adopted for data analysis illustrates the iterative approach between the recursive link back to the relevant theories and concepts. A single case study approach is presented as a suitable method to investigate this phenomena in its natural context, as it allows for the subjective and contextual experiences of the participants supported by in-depth interviewing and documentation analysis. Data is analysed using both manual and NVivo approaches. To complete the ambition for a comprehensive network perspective this study conducted interviews with all network nodes in the EU research network. Coverage of all network nodes to gain insights from each member of the network rather than dilute the investigation to a portion of the network, is considered a crucial research design choice. In addition, 
use of archival data is common in this domain and a documentation analysis was conducted for this study (Greer and Lei 2012; Geisler, 2003, Kirschner et al., 2004; Perkmann and Schildt, 2015).

To identify convergence of themes and patterns across interviews, the data and literature was iteratively examined with initial codes or themes developed based on a pattern between the data and the conceptual framework in line with literature and a priori themes (Hite, 2005; McGrath and O'Toole, 2014; Miles and Huberman, 1994; Yin, 2003). Coding in this manner facilitated insight and comparison through segmenting the data into units. This technique gave the researcher the flexibility to expand the codes and hierarchies in NVivo to enable interpretations to be made and findings to be finalised. The application of this technique in conjunction with the extensive use of the memoing function in NVivo facilitated the interpretation of findings.

An iterative approach was adopted, the interview transcripts (A-E) were imported into NVivo, a preliminary analysis (basic visuals) performed, followed by the remaining interview transcripts (F-J) and the 37 news blogs and documentation as identified in Table 4.

Table 4: Documentation Register

\begin{tabular}{|c|c|c|c|}
\hline Document/Artefact Title & $\begin{array}{l}\text { Relative importance to } \\
\text { research }\end{array}$ & $\begin{array}{l}\text { Level of } \\
\text { accessibility }\end{array}$ & Comments/reflection \\
\hline \multirow{2}{*}{$\begin{array}{l}\text { Factsheet } \\
\text { Website }\end{array}$} & Low & Public & Background information \\
\hline & Medium & Public & $\begin{array}{l}\text { Background information and event } \\
\text { descriptions }\end{array}$ \\
\hline \multirow{3}{*}{$\begin{array}{l}\text { Grant Agreement } \\
\text { Project brochure } \\
\text { Initial Dissemination plan }\end{array}$} & Medium & Confidential & Detail on project implementation \\
\hline & Low & Public & Background information \\
\hline & Medium & Confidential & $\begin{array}{l}\text { Identified dissemination, position and } \\
\text { exploitation strategy. Includes context } \\
\text { and links between network nodes and } \\
\text { external expert panel and the vision of } \\
\text { the individuals. }\end{array}$ \\
\hline Project Plan & Medium & Confidential & $\begin{array}{l}\text { Background information and } \\
\text { implementation processes. }\end{array}$ \\
\hline \multirow{2}{*}{$\begin{array}{l}\text { Industrial and Business } \\
\text { Showcase } \\
\text { Dissemination Materials }\end{array}$} & High & Confidential & $\begin{array}{l}\text { Positioning of the AquaSmart solution } \\
\text { toward market uptake. }\end{array}$ \\
\hline & High & Confidential & $\begin{array}{l}\text { Detail on dissemination, events, } \\
\text { publications, and social media. Identified } \\
\text { links and relationships in network. }\end{array}$ \\
\hline Dissemination Plan & High & Confidential & $\begin{array}{l}\text { Presented the dissemination results, } \\
\text { standardisation and network vision. }\end{array}$ \\
\hline \multirow{2}{*}{$\begin{array}{l}\text { Big data CEN Standards } \\
\text { workshop report } \\
\text { Final Dissemination Plan }\end{array}$} & High & Public & $\begin{array}{l}\text { Provided depth of impact and relational } \\
\text { instances. }\end{array}$ \\
\hline & High & Confidential & $\begin{array}{l}\text { Reported on results of dissemination } \\
\text { and identified main actors of } \\
\text { dissemination. }\end{array}$ \\
\hline
\end{tabular}

Table 5 below identifies the documentation that was analysed and its usefulness to the research implementation.

Table 5: Summary of Documentation Analysis Deployed

\begin{tabular}{|c|c|c|c|c|c|}
\hline Document Type & Source & $\begin{array}{l}\text { Inform } \\
\text { Interview } \\
\text { Questions }\end{array}$ & $\begin{array}{l}\text { Augment } \\
\text { Interview } \\
\text { Data }\end{array}$ & $\begin{array}{l}\text { Corroborate } \\
\text { Interview Data }\end{array}$ & $\begin{array}{l}\text { Provide } \\
\text { Background }\end{array}$ \\
\hline \multirow{7}{*}{$\begin{array}{l}\text { Project Brochure } \\
\text { Initial Dissemination Plan } \\
\text { Project Plan } \\
\text { Industrial and Business Showcase } \\
\text { Dissemination Materials } \\
\text { Dissemination Plan } \\
\text { Big Data CEN Standards Workshop } \\
\text { Report }\end{array}$} & External & $\mathrm{x}$ & & & $x$ \\
\hline & Internal & & $X$ & $X$ & \\
\hline & Internal & $x$ & $x$ & $x$ & $x$ \\
\hline & Internal & & $x$ & $x$ & \\
\hline & Internal & $x$ & & & $x$ \\
\hline & Internal & $\mathrm{X}$ & & & $x$ \\
\hline & Internal & & $x$ & $x$ & \\
\hline \multirow{2}{*}{$\begin{array}{l}\text { Final Dissemination Plan } \\
\text { Web-Home Pages }\end{array}$} & Internal & & $x$ & $x$ & $x$ \\
\hline & External & $x$ & & & $x$ \\
\hline
\end{tabular}




\begin{tabular}{|c|c|c|c|c|c|}
\hline Document Type & Source & $\begin{array}{l}\text { Inform } \\
\text { Interview } \\
\text { Questions }\end{array}$ & $\begin{array}{l}\text { Augment } \\
\text { Interview } \\
\text { Data }\end{array}$ & $\begin{array}{l}\text { Corroborate } \\
\text { Interview Data }\end{array}$ & $\begin{array}{l}\text { Provide } \\
\text { Background }\end{array}$ \\
\hline \multirow{2}{*}{$\begin{array}{l}\text { Web-Blog Articles } \\
\text { Organisational Chart }\end{array}$} & External & & $\mathrm{X}$ & $x$ & \\
\hline & Internal & & & & $x$ \\
\hline
\end{tabular}

\section{Research Context: AquaSmart}

This research adopts a case study approach examining an EU funded research network, called AquaSmart ${ }^{1}$ (Aquaculture Smart and Open Data Analytics as a Service). It is a high-tech ${ }^{2}$ information communication technology (ICT) network funded by the EU Horizon 2020 research programme over the period 2016-2018. AquaSmart is using ICT to improve its data utilization and operations. High-tech organisations provide a rich context for the study, given their heavy reliance on network ties that stem from, and are embedded within, social relationships (Larson and Starr, 1993). The high-tech sector of the economy uses the most advanced technology available, it is often seen as having the most potential for future growth and this perception has led to high investment in high-tech sectors of the economy. The European Commission places a large emphasis on its $\mathrm{H} 2020$ research programme to foster innovation and competitiveness in Europe through excellence in ICT research and development. The choice of a high-tech context for this case study builds upon recent research on research networks in high-technology industries (Perkmann et al., 2013; Perkmann and Schildt, 2015; Perkmann et al., 2015; Scherngell and Barber, 2011; Scherngell and Lata, 2013; Wanzenböck, Scherngell and Lata, 2015; Hite, 2005).

In Europe, the Aquaculture industry accounts for about 20 per cent of fish production and directly employs some 80,000 people. It is the fastest growing animal food-producing sector in the world. Global forecast on production is set to increase from 45 million tons in 2014 to 85 million by 2030. The European Commission has repeatedly called for prompt research action to stimulate large numbers of aquaculture businesses with ICT innovations. Aquaculture is identified as a key focal point of the EU's Blue Growth Strategy ${ }^{3}$. Furthermore, investment of $€ 1.13$ billion has been allocated to aquaculture research through the European Maritime and Fisheries Fund ${ }^{4}$ (EMFF) and other cross-cutting topics in H2020 during 20018 and 2019 include $€ 170$ million $^{5}$ funding. Aquaculture is the fastest growing animal food producing sector in the world. Global forecast on production is set to increase from 45 million tons in 2014 to 85 million by 2030 .

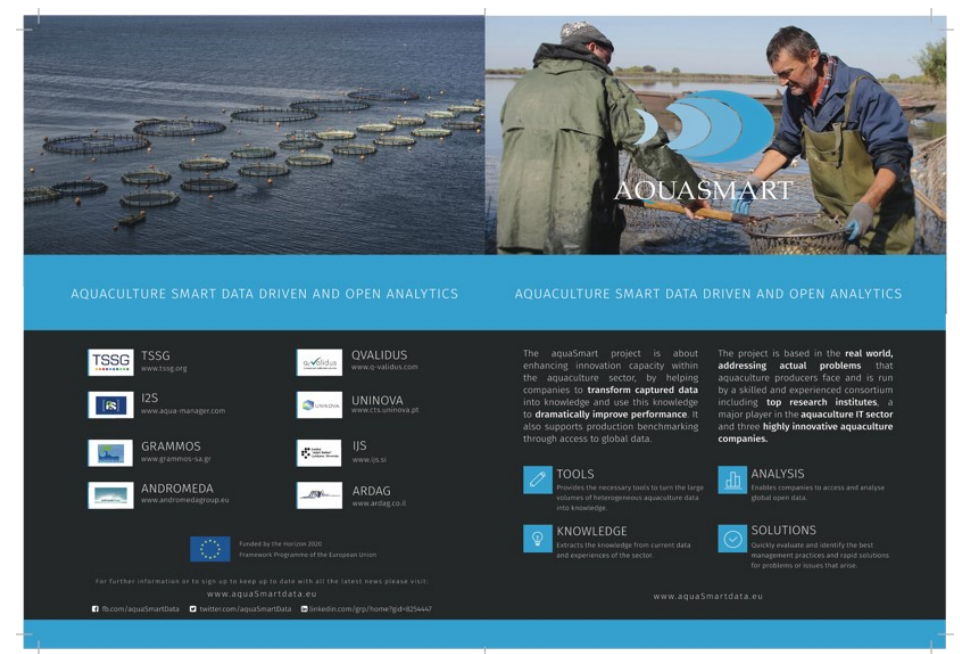

Figure 2:AquaSmart Context

The AquaSmart consortium comprises of 7 partners from 5 member states and 1 associated country. The AquaSmart network includes a diverse mix of researchers, fish farmers and ICT experts. The AquaSmart network includes participants from industry and academic organisations. The network consisted of 1 micro organisation,

\footnotetext{
${ }^{1}$ http://www.AquaSmartdata.eu

${ }^{2}$ https://www.een-ireland.ie/eei/assets/documents/uploaded/general/ICT\%20Fact\%20sheet.pdf

${ }^{3} \mathrm{http}: / /$ ec.europa.eu/maritimeaffairs/policy/blue_growth

${ }^{4}$ https://ec.europa.eu/fisheries/cfp/aquaculture/funding_en

${ }^{5}$ http://ec.europa.eu/research/participants/portal/desktop/en/opportunities/h2020/topics/dt-bg-04-2018-2019.html
} 
3 small organisations, 2 medium organisations and 2 large organisations. The network included 3 academic partners, 3 end-user partners and 2 ICT partners. $90 \%$ of the participants were male. The following section (section 5) outlines the adopted research methodology.

\section{Findings}

This section presents the findings and provides evidence to illuminate stories and accounts of the network nodes (individuals active in the network) and their activities in collaborative research. The literature identifies difficulties in relation to creating and managing research networks; the empirical results provide insights to inform researchers toward their prevention and resolution (Lyall, Meagher and Bruce, 2015; Melese et al., 2009; Mehlman et al., 2010).

Table 6: Summary of key findings

\begin{tabular}{|c|c|c|}
\hline Finding & Description & Application \\
\hline$F 1$ & $\begin{array}{l}\text { Network formation and network hopping. } \\
\text { Formation of a new company from EU funded research goes beyond } \\
\text { one network into another and is dependent on the drive of } \\
\text { individuals with support of organisations. }\end{array}$ & Impact of the research \\
\hline F2 & $\begin{array}{l}\text { Diversity within research networks is conducive to a wide array of } \\
\text { impact metrics. Optimising the creation of research networks } \\
\text { (industry and academic collaboration) } \\
\text { Incentivising mixed networks is essential for innovation. The } \\
\text { network configuration for ICT EU research needs weak and strong } \\
\text { ties to facilitate integration of technical and commercial expertise. }\end{array}$ & Network configuration \\
\hline F3 & $\begin{array}{l}\text { Social aspects within the diverse network configurations assisted } \\
\text { the prevention and resolution of issues. The findings presented } \\
\text { evidence of the difficulties encountered building common } \\
\text { understanding within multi-disciplinary research networks and } \\
\text { between industry and academic networks. }\end{array}$ & Tensions within the network. \\
\hline$F 4$ & $\begin{array}{l}\text { Key roles as enablers to manage the research network (bridge, } \\
\text { motivator, entrepreneur). The participants described cooperation } \\
\text { and collaboration in the network. A network of diverse participants } \\
\text { included incidents of reciprocity, exchange and regular cooperation } \\
\text { and the challenges therein. The impact of these roles within the } \\
\text { network included sustainability and progression of the network and } \\
\text { its research output. }\end{array}$ & Impact of the research \\
\hline$F 5$ & $\begin{array}{l}\text { Difficulties encountered with managing research networks. Intra- } \\
\text { network competition increases tensions and impact trust. Trust is a } \\
\text { major influencing factor in interpersonal relationships and can be } \\
\text { linked to operations of the network, output of the network, } \\
\text { enablers and barriers within the network. The evidence supported } \\
\text { the importance of trust being central to behaviours in networks. } \\
\text { Additionally, the research highlighted the funding differentiation } \\
\text { impact of network relationships. }\end{array}$ & $\begin{array}{l}\text { Barriers \& resolutions. } \\
\text { Role of the research funding } \\
\text { agency to alleviate tensions. }\end{array}$ \\
\hline F6 & $\begin{array}{l}\text { Tangible economic impact (e.g. skills and competency } \\
\text { enhancement, new service offerings were critical). Research } \\
\text { networks are encouraged under the EU Digital Agenda. This } \\
\text { research presented the different new service offerings from its } \\
\text { partner organisations. }\end{array}$ & Impact of the research \\
\hline F7 & $\begin{array}{l}\text { This research found that the measurement of research network } \\
\text { results and performance impact are collected and analysed too } \\
\text { early to determine evaluation award. }\end{array}$ & $\begin{array}{l}\text { Measurement of research } \\
\text { impact beyond funding period. }\end{array}$ \\
\hline
\end{tabular}

\subsection{F1 Network formation and network hopping}

Formation of a new company from funded research goes beyond one network into another and is dependent on the drive of individuals with support of organisations. The formation of research networks is often not incubated as a new seed, its stems from previous growth and is cultivated. New research networks are formed from old alliances with the inclusion of new elements, new companies/spinouts emerge from research. The study highlighted that there is sometimes a lack of openness in research networks. The existence of closed networks in consortia are frustrating to non-members; they build upon previous calls, the networks are longitudinal in nature and have informal inclusion and exclusion criteria. One of the research participant's 
suggestion was to include a mechanism to ensure openness and adopt criteria for evaluation or weighting for openness at the stage of network formation. Short-term networks often decide to cocoon themselves for a while to leverage their comfort of knowing each other well in relation to professional competencies and social nuances. Creating sub-communities in funded research/working groups has its advantages and disadvantages as you may be eliminating the positive innovative effect that weak ties and structural holes have on a network. However, if the funding agency values the work of Burt (1992) and Granovetter $(1985 ; 1992)$ as pertinent to reaching their funding objectives (increase in novel ideas) then perhaps they need to consider introducing a mechanism to facilitate openness in research networks. The evidence highlighted that prior engagement with funded research positively affected the openness within the network. Thus, it leads to the belief that openness can be managed and having network members familiar with funded research can influence the openness of the network.

If we compare a EU funded network (or formation of a new network) to a new job, the individual sends in a CV (proposal) to gain employment, just like a competitive funding application. Upon granting of the funding /acceptance of the job there is a period of time under probation where the employee is guided and both parties have to comply to their contractual conditions. While some may see funded networks as temporary networks, it is my belief that they are re-used for many different endeavours and are a worthwhile investment for longitudinal returns. For the proposal writing phase, the funding institute has recognised the difficulties for partners to meet-up and have established mechanisms similar to social networks online partner search functionality, partnering events, LinkedIn groups and databases of previous research to assist researchers in this network formation phase. Self-organising networks; configurations of networks emerge and disband, network hopping, weak and strong ties are all longitudinal, it takes a different perspective to see that research network engagements are not temporary or short-term.

From an economic perspective, a major achievement from an investment or funding institution is the creation of new jobs new companies, while at the early stages of negotiation it is clear that the network in this study has identified the emergence of a new company as a real possibility. Interviewee A believes the formation of a new company is imminent, however, there is little detail at this stage, "a new company.... that is still being discussed". The criteria for inclusion and exclusion of individuals or organisations is not evident.

\subsection{F2 Network configuration}

This paper discusses network configuration in detail and describes the nuances in the case study in relation to research network formation, management and sustainability. The network configuration for ICT research needs weak and strong ties to facilitate integration of technical and commercial expertise. In this case network centrality, idea generation and wide network knowledge were pivotal to network formation with specific roles emerging that impacted progress, opportunity management and problem resolution. The formation of the network is a crucial and time-consuming element of research initialisation and prior relationships was a significant factor for the creation of this research network. Specifically trust was identified as an enabler, the network formation stage depended on prior relationships to engage end-users.

Often, collaborative, funded research is multi-disciplinary connecting ICT with an application domain. The network configuration for ICT research needs weak and strong ties to facilitate integration of technical and commercial expertise. Diversity within the network is conducive to a wide array of impact metrics. While strong ties were apparent, in some cases weak ties and structural holes were considered significant advantages for this research network. Network diversity is critical to solving real-world problems and needs through multidisciplinary research. The results from this research contributes directly to theory by providing rich insights in structural embeddedness. For example, the division between the type of network member; technical and business oriented. The contribution to practice equips future research network members with the knowhow to purse an optimised network strategy, cognisant of social and economic aspects. In addition, the research management function now has insights to enablers and barriers of structural embeddedness which supports their operations.

The research provides insights that highlights the role of the academic entrepreneur and their position in the network to push the boundaries of the ICT solution to meet the current and visionary needs of the application domain. It was clear that the role of academics within the network is akin to quasi-business in relation to the impact of research at an economic level and an extension of their competencies and service provision capabilities. Practitioners also obtained insights to the difficulties of different funding instruments to attract 
academic partners that are focussed solely on new knowledge and not concerned with research implementation. There was evidence that this potentially creates a barrier to cooperation and collaboration. These aspects of the network dynamics were evident through the examples that the network members described facilitated by the exploratory nature of the research and the flexibility to explain the nuances within the network in detail.

The convenience of clustering strong ties for network strategy is evident. This increases the limitations in relation to quality of research output, lost innovation opportunity and a diminishing impact on disruptive technologies. Identified barriers included inequality in funding ratios for different partner organisations, location of member states, and brevity of the funded network duration. Competition was initially a barrier but as the research network matured there is evidence of a joint vision to penetrate the global market. Diversity of participants was key to successfully reach the network objective but its challenges were apparent and impeding progress at times. The following paragraphs provide some of the in-depth evidence that supports the insights in relation to formation and management of research networks.

\subsubsection{Prior relationships Academia V Industry}

The research network benefited in its incubation from the existence of prior relationships:

Participant $D$ from Andromeda states:

"We got involved because of our previous engagement with the Greek company and their AquaManager tool. I think since we had already established good collaboration between our technicians and their technicians, they initiated our involvement in this network".

There was an apparent divide between the ICT researchers and end-users, this prior relationship was a key element of this network's formation; it is well-known in a practitioners' environment, that research necessitates collaboration with end-users to apply a technical solution to an industry challenge. The consortia building (network formation) activity in a research network is often associated with the individual who has the idea for the research or the research network connections. For this research, there were two individuals involved in the formation of the network. Participant A described the depth of the relationship between the founding members of the AquaSmart network when stating:

"XX brought us into the network. His whole idea is to build a big family of workers to work together with a common goal. The family would be people that he has worked with before, say researchers, that he has met through research projects or projects that he has reviewed, and he has picked out partners liked how they work and then brought them together to form a consortium".

This comparison to a family was repeated in different instances in the data. When asked, "how did you join the network?" Participant I replied, "I didn't join it, I created it". There was obvious pride in this statement around the success of the network, and the participant did disclose the positive and negative examples of how the network functioned.

\subsubsection{Challenges of convergence of multi-disciplinary expertise}

Participant $\mathrm{H}$ seems to have been invited into the network purely because of competencies in machine learning and multi-language translation. It was interesting to see that they were the last to be invited into the network and this suggests an emerging gap in the competencies required to implement the planned research. Necessity appears as a significant consideration for network formation. Participant $\mathrm{G}$ emphasised the challenges and complexities that the network encountered upon implementation:

"There was a lot of norming, forming and storming in the first period. The end-users had great expertise and knew vastly more than the techies and that was an important initial dynamic. One of the key phrases from Participant $X$ was that you guys don't know how to talk fishy"

This reference to 'talk fishy' was mentioned in a number of interviews and highlighted the difficulties that jargon and knowledge represented in the network. Furthermore Participant G describes how "it took time to understand each other. Face to face meetings are crucial toward understanding different partners". Partner H highlighted that network exclusion is evident in some cases:

"Groups form informal networks and they don't let anyone else in. These closed shop type networks occur when there are calls that build on previous calls with closed consortia". 
Participant $\mathrm{C}$ was also a founding member of the network and played a pivotal role in the network formation. He affirmed that the research was his idea. Subsequently, he invited three of his clients into the network, and then approached Participant I who had network know-how, and they formed the network together. While both Participant $\mathrm{C}$ and Participant I had strong ties and considered that they led the network formation, the other eight participants had no strong ties. It is clear that Participant $C$ urged the non-technical partners to join the network and Participant I encouraged the technical partners.

\subsection{F3 Social aspects}

Social aspects of diverse network configurations aid prevention and resolution of difficulties encountered e.g. toward building common understanding. The jargon used by the application domain created a division within the network and as a result the participants reported an elongated incubation period within which time network cohesion was absent and tensions were high. Eventually with careful intervention by the bridging partner and the coordinator the communication challenges between the diverse research participants were resolved. Following on, friendships were evident in this research network and facilitated enhancement of skills and competencies and enabled effective problem resolution. Additionally, trust, cooperation, reciprocity and exchange emerged as significant positive attributes. Openness and trust were explicitly boosted at meetings where the partners were able to deepen their relationships through the informal dinners, mingling at breaktimes and joint exercise programs between participants.

Funding and costs (e.g. flights, meals) in relation to inter-organisational activity were cited as significant influencing factors on network progress, bridging the divide between the diverse network configurations. In addition, deep interpersonal relationships matured as participants referred to the network as family and akin to marriage.

Whilst collaborative research might allude to co-creation of knowledge, it was evident that some participants in the research network did not intend to pursue such objectives, this resulted in some isolation within the network.

\subsection{F4 Enabling roles}

The evidence from this research indicates that there were specific roles that individuals adopted to enhance the workings of the research network. This began with the formation of the network, through the management of the specific research and included the sustainability of the research toward commercialisation. Significantly, the depth of the relationships within the research network contributed to the effectiveness of these functions. For example, the participants highlighted a unique approach to motivation as a significant enabler. A specific individual within the research network adopted an explicit motivational role that featured at face to face meetings and conference calls. Furthermore, the research shows that this unique 'motivator' role had a positive effect in relation to problem resolution and work ethics, supported by an effective coordinator which resulted in high functioning collaboration and cooperation. This supports and extends the literature in relation to the need for inspiring leadership in research to motivate and support the researchers, the capacity building and investment in catalytic activities for active management is critical (Lyall, Meagher and Bruce, 2015) .

The structure of the network illustrated how one network member provided a bridge between ICT and the application domain. As the formation of the network and prior relationships already illustrated building bridges between network participants was critical and challenging,. Centrality was evident within the network and the initiating participants highlighted their skills in relation to idea generation, wide network knowledge, and knowhow as imperative to the success of the network. Participant D cited a main challenge as the division between academic and industrial participants and a gap in knowledge between the two sets of participants:

"We had to build a bridge between the two distinct partner groups (academia and industry) and address

the way we handle and distinguish important knowledge".

This highlights the differences between a temporary proposal network and a more stable research implementation. This role of a bridge was required as the gaps between perceptions and views were sufficiently sizeable that it affected the output and the performance of the network. The gaps in understanding were alleviated during social events and trust-building work activities. Participant A and Participant I cited culture and language as contributing factors "different cultures and different work practices can have a significant impact on the network ". Furthermore, Participant F identified location as a difficulty for collaboration, such as schedules for meetings and travelling for plenaries, which were identified as difficult but manageable. 


\subsection{F5 Difficulties encountered with managing research networks}

Collaborative funded research involves individual and collective objectives and visions, it is inevitable that bringing inter-disciplinary researchers together can have difficulties and challenges. Within this research network it was clear from the outset that tensions were high between ICT organisations and the application area (aquaculture). Particularly, the research presents instances of anxiety in relation to sharing information and how this was resolved. Whilst the benefits of collaborative research networks are undisputed the fact that the network is conducting research does not override the requirement to protect trade secrets. This section details intra-network competition, tensions and trust issues triggered by initiatives such as EU open data policy.

It was clear from the empirical evidence that the open data policy and data sharing had conflicting priorities with competitiveness and that intra-network competition and the fear of sharing production data needed to be addressed and mechanisms employed to mitigate risk and alleviate tensions. Initially, open data compliance adversely effected the relationships within the network. Competitive production data tensions were difficult to resolve and complexity in relation to competition was evident particularly in relation to the end-users. However, techniques such as anonymisation facilitated the sharing of data among unfamiliar network parties. Thus, competition was initially a barrier but mechanisms were established to overcome this challenge and these can be recycled for further research management resolution.

Additionally, other barriers noted included a funding disparity among research networks, physical location of eligible partners and brevity of the funded network duration. From a policy perspective, funding agencies can further understand the structural embeddedness of research networks and the complexities therein. The study findings indicate that the differentiation between partner types and funding creates a tension in the network toward inequality between partners. Furthermore, this leads to the occurrence of closed shop networks relying on prior relationships and positioning. The divide between industry and academic partners is exacerbated through the funding model that gives financial preference to academic partners. The funding agency should take this into consideration and amend its funding policy as the impact of unbalanced support in collaborative environments can be negative. Whilst cognisant of the need to get commitment from industry stakeholders the funding agency also needs to understand fully that network members need to be treated equally or tensions will arise. Furthermore, the research needs critical input from industry partners in the form of market requirements, product and service user scenarios and access to production data. The funding agency needs to listen and nurture its research networks, they are organic and susceptible to environmental influences. Feedback from researchers can ensure its sustainability for returning researchers, innovators and entrepreneurs, to encourage existing members to remain and new members to join. Successful competitive funding proposals are difficult to attain, the effort required is significant and the success rates are low (approx. $5-15 \%$ in H2020 ICT). For example, consideration of social aspects within the research network; trust, friendships, motivation. Interpersonal relationships in the research network are a significant enabler to support research optimisation. The funding agency acts as a gatekeeper for the knowledge economy, the wealth of expertise and knowledge that peers engage in during the network activities facilitate co-knowledge creation and enhancement of their competencies and skills. It is not always about network growth but quality and depth of relationships can enable further deep learning and technology advancements.

The empirical evidence physical location of partners within the network is significant for managing face to face meetings and resolution of issues. Whilst a network has funds allocated for project meetings, the resources (cost, time, distance) can vary depending on the network. Investment in catalytic activities such as ideation workshops, meetings for conflict resolution might enhance the research management function. This study shows that face to face meetings and social interaction activities are integral to build trust within a research network. The high levels of trust between network members in this case study impacted competencies, problem resolution and initiated an informal running group within the network. These insights deepen our knowledge of effective research networks and provide the scaffolding for long-lasting structural innovation. Interdisciplinary research encompasses social and natural science which needs a balanced rather than asymmetric contribution. Furthermore, the literature provides insights into the role of the funding agency and this research gives additional empirical evidence in relation to governance, disappointment and network bullying type obstructions and their resolution toward optimisation of network effectiveness (Lyall, Meagher and Bruce, 2015). 


\subsubsection{Building trust to alleviate research challenges and talk a common language}

Trust is central to each and every inter-personal relationship and it affects behaviours of those in networks (Neves and Caetano, 2006). There were several participants who mentioned temporal considerations in relation to building up trust and its connection with the effectiveness of the network. Participant A initially mentioned one or two months to build up trust, but as we continued our discussion, it was recorded as significantly longer.

Participant A maintains "the first meeting is a kick-off meeting, then you have 3 months of work before the next meeting so that's kind of 4 months really to get going". Similarly, Participant E believed that there was trust between partners by the milestone of the second meeting when describing how "at first, we didn't know each other well, but we worked closely together and we faced issues of trust which improved by the second and subsequent meetings". Participant $C$ believes it took about a year to build trust between the network participants. Furthermore, Participant $\mathrm{A}$ asserts that the jargon in relation to aquaculture and technology created an adverse impact on trust within the network, explaining that "it was 8-9 months into the project when we were able to talk a common language". It can be envisaged how this gap in understanding might impact other elements of the network. Many of the network participants linked the face to face aspects of the project; meals out, coffee breaks and informal discussions as instrumental to alleviating the problems encountered in the network that were linked with trust. Participant J highlights "if you only communicate with someone through a conference call it can be difficult to understand and get the context of someone. Whereas, when you see what they look like and their manner, then relations can be much easier".

Following on, Participant $\mathrm{C}$ gave examples of comparable research networks where trust between partners was not evident and this had a negative impact on the research network output:

"I think it's the people that made the difference. Previously I worked with a European project and there were cases that partners were trying to hide things from the others and take ideas from other people. In AquaSmart I never went to a meeting thinking that I had to be careful about what I say or how I present something, and I believe it was the same for the other partners in AquaSmart".

The network composition is a key factor to consider when a diverse network of researchers needs to understand each other's knowledge. Participant $D$ highlights the understanding needed for both stakeholder types to handle knowledge and work with different jargon. They saw the need to build a bridge between them and take into consideration the gaps in knowledge and understanding as associated with their organisation and personal profiles. This was particularly relevant in relation to prioritisation and identification of crucial knowledge and knowledge handling. This identifies another disconnect between partner types as jargon was already identified as significant. Participant I provided some advice and insights to help improve trust and coordination in a research network, citing listening skills, respect, diplomacy and problem-solving skills as critical competencies.

It is clear that the jargon used created a division within the network and as a result the participants reported an elongated incubation period within which time network cohesion was absent and tensions were high. The formation of the network and prior relationships played a significant role in the configuration of the network. Building bridges between network participants was challenging, trust and anger were identified as significant issues.

Research networks are homes to test and validate ideas and procedures. These conditions can act as a training ground to support and nurture European researchers. However, depending on the configuration of the network, the ability to attach an economic value to improvements in competencies and skills is not guaranteed. The complexities involved centre on the composition of the network, willingness, and the capacity of participants to draw on inter-personal interactions. This study demonstrated great willingness and capacity that was leveraged to improve network competencies. Common understanding, ability to talk a common language and understand the requirements and capability of the research along with the collective know-how and technical implementation was key to realisation of the research achievements.

The network members placed a high value on the expansion of their network and possible future opportunities available to the network. However, evidence also supported the case that different types of network members have little capacity to resource weak ties and network engagement outside of their existing closed network. For example, priority is placed on common industry networking events as these were perceived more strategic and core business for the industry partners than research networks. Granovetter (1985) recommends that 
embeddedness be further investigated as behaviour and institutions are so consumed by ongoing social relations.

\subsection{F6 Tangible economic impact (e.g. upskilling, new service offerings)}

The evidence from the case study reported pride in the quality of the research output, the results they were developing, and the depth to which friendships and interpersonal relationships had cultivated. New service offerings and the ability of partners to disseminate on a global level were emphasised. Commitment and trust impacted the research output and expectations of network participants.

Depth and wealth of industrial knowledge held by the end-users provided essential data while also it created challenges in relation to managing the research project. Each participant is an expert in their own area, collaborative research often aims to achieve multiple objectives, participants have individual and collective ambition and vision. The network created a joint vision to penetrate the global market. Diversity of participants was key to successfully reaching the network objective, but its challenges were apparent and impeding progress at times. Trust, cooperation, reciprocity exchange and friendships emerged as significant attributes. Links between social and economic aspects were evident as friendships and tensions connected the quality of the network output. Co-creation of knowledge was perceived in some relationships and absent in others where contribution to research was downgraded as the scope of the research changed. Skills enhancement in competencies and the expansion of personal and organisational networks were cited as favourable to the network participants. The emergence of new service offerings and a widening of global contacts where network participants disseminated on a global level, were emphasised along with the research network attaining a number one position in Google keyword rankings. When divided into industry focus the non-ICT participants (end-users) attributed the economic aspects as the most relevant area.

\subsection{F7 Measurement of research network results and performance impact are collected and analysed too early to determine evaluation award.}

EU funded research follows a rigorous evaluation process at proposal stage and is reviewed periodically during the implementation of the research. This study claims that whilst it is necessary to evaluate the success or failure of the research at the end of the funded engagement it concludes that this stage gives insufficient weighting to the full impact or exploitation of the research. Whilst a full solution for measuring the longer term effects of research network is not yet evident the study suggests explicit monitoring of output in relation to new company formation and provision of new service and product offerings. Thus, the funding duration and sustainability of the research network are important considerations and the provision of follow-on grants should be explored further.

The function that funding agencies play in relation to enhancing our economy and society through ICT research advancement is significant, and the major stakeholders (funding agency and research network members) need to work together to ensure optimum effectiveness is achieved and European citizens can benefit. From a policy perspective, this study gives funding agencies insight to further understand the structural embeddedness of research networks and the complexities therein. It is clear that the role of the funding agency goes beyond the specific duration of any particular fund, and the sustainability, access to follow-on funds and nurturing of research networks holds potential. Currently, the funding agency provisions researchers with facilities toward formation techniques and there is opportunity to extend this and include network analysis functionality to give researchers a more resources to manage research networks.

\section{Conclusion and recommendations}

Structural embeddedness refers to the quality and configuration of the interactions between nodes in a network. The data has identified insights in relation to the structural embeddedness of research networks, the distinct qualities, economic and social characteristics prevalent in these types of networks. From the findings, many challenges and enablers have been identified within research networks. For example, the development of disruptive technologies is reliant on weak ties, even though prior relationships were evident. Communication within a network is critical, jargon and misunderstanding impact network optimisation. Social elements such as motivation, pride, friendships and trust play a significant role in the realisation of successful network outcomes.

Inequality in funding was identified between nodes and competition between nodes required intervention and policies to enable solutions. 
The results from this research contributes directly to theory in two ways, firstly, by providing rich insights in structural embeddedness. For example, the division between the type of network member; technical and business oriented. This division in multi-disciplinary research where industry and academia collaborate can result in asymmetric contributions rather than balanced solutions. The richness of the research results will usually outweigh the barriers and obstacles encountered but the provision of mechanisms and planning for common issues can positively impact the level of achievements.

The empirical evidence from the research details anxiety in relation to understanding each other and the research information and how this was resolved. Specifically, the structure of the network illustrated how one network member provided a bridge between researchers.

Secondly, structural embeddedness has not previously been investigated in this area, it provides novel contextual insights. Technology progression strands society and its application areas are many, whilst this case study investigated ICT and Aquaculture, in the digital age technology is ubiquitous and many of the concepts encountered in this case study are pertinent.

The research describes the difficulties encountered by the research network in adopting ICT solutions and the complexities of sharing data with other network members. These insights and their tentative solutions provide a detailed picture of the network operations. This unravelling of the complexities of managing research networks gives practitioners extensions to the their toolbox to prepare for and react to barriers and obstacles that are inevitable in multi-disciplinary research networks. Network formation can be optimised and tailored for their own specific objectives in advance of the grant being awarded so that researchers can minimise disruption and focus on the research with a supportive research management function. It is evident that these insights provide a deeper understanding of managing research not achievable through quantitative methods.

The contribution to practice equips future research network members with the knowhow to purse an optimised network strategy, cognisant of social and economic aspects. In addition, the research management function now has insights to enablers and barriers of structural embeddedness which supports their operations. Particularly the findings illustrate the necessity to actively address jargon within multi-disciplinary research networks especially relevant with the increase in multi-disciplinary research. For research networks a mix of weak and strong ties is recommended, however sufficient incubation is required to enhance socialisation. Prior relationships are common within research networks but structural holes and weak ties are also common. These aspects of the network dynamics were evident through the examples that the network members described facilitated by the exploratory nature of the research and the flexibility to explain the nuances within the network in detail.

From a policy perspective, funding agencies can further understand the structural embeddedness of research networks and the complexities therein. As guardians of research and resource management of public finances in relation to a productive economy, health society and sustainable world the governance aspects need to extend to optimisation of research networks.

Disparity of funding among members of a research network highlights unbalanced support in collaborative environments which can be negative. The role of the policy makers goes beyond compliance and includes cocooning of researchers in a suitably provisioned environment, the ubiquitous nature of technology in our society and need for multi-disciplinary research networks is evident and needs to be fully addressed by policy makers.

Citizens and industry partners need support and representation toward accurate development of market requirements, product and service user scenarios and access to production data. The funding agency needs to listen and nurture its research networks, they are organic and susceptible to environmental influences. Feedback from researchers can ensure its sustainability for returning researchers, innovators and entrepreneurs, to encourage existing members to remain and new members to join. The funding agency acts as a gatekeeper for the knowledge economy, the wealth of expertise and knowledge that research networks encompass are not limited to network growth but quality and depth of relationships can enable further deep learning and technology advancements. 


\section{References}

Agarwal, R. and Selen, W., 2009. Dynamic capability building in service value networks for achieving service innovation, Decision Sciences, 40(3), pp. 431-475.

Agarwal, R. and Selen, W., 2011. Multi-dimensional nature of service innovation: Operationalisation of the elevated service offerings construct in collaborative service organisations, International Journal of Operations \& Production Management, 31(11), pp. 1164-1192.

Baron, R. A. and Markman, G. D., 2003. Beyond social capital: The role of entrepreneurs' social competence in their financial success', Journal of Business Venturing, 18(1), pp. 41-60.

Beckmann, V. and Padmanabhan, M., 2009. Analysing institutions: What method to apply?, In V. Beckmann and M.A. Padmanabhan (Eds). Institutions and Sustainability, Dordrecht: Springer, pp. 341-371.

Bienenstock, E. J. and Bonacich, P., 1997. Network exchange as a cooperative game, Rationality and Society, 9(1), pp. 3765.

Blau, P. M., 1964. Exchange and power in social life, New York:Transaction Publishers.

Bolzani, D., Fini, R., Grimaldi, R., Santoni, S. and Sobrero, M., 2014. Fifteen years of academic entrepreneurship in Italy: Evidence from the taste project. Technical Report; University of Bologna, Italy.

Borgatti, S. P., Mehra, A., Brass, D. J. and Labianca, G., 2009. Network analysis in the social sciences', Science, 323, pp. 892895.

Bourdieu, P., 1986. The forms of capital. In I. Szeman and T. Kaposy (Eds). 2010. Cultural theory: An anthology, UK: WileyBlackwell, pp. 81-93.

Bourdieu, P. and Wacquant, L. J., 1992. An invitation to reflexive sociology, Cambridge: Polity Press.

Bozeman, B. and Gaughan, M., 2007. Impacts of grants and contracts on academic researchers' interactions with industry, Research Policy, 36(5), pp. 694-707.

Bozeman, B. and Melkers, J., 2013. Peer review and evaluation of R\&D Impacts. In: B. Bozeman and J. Melkers (Eds). Evaluating R\&D impacts: Methods and practice, New York; Springer Science \& Business Media pp. 79-98.

Braun, V. and Clarke, V., 2006. Using thematic analysis in psychology, Qualitative Research in Psychology, 3(2), pp. 77-101.

Brown, T. H., 2015. Exploring new learning paradigms in ODL: A reflection on the paper of Barber, Donnelly and Rizvi (2013): "An avalanche is coming: Higher education and the revolution ahead"', The International Review of Research in Open and Distributed Learning, 16(4), pp. 227-234.

Burrell, G. and Morgan, G., 1979. Two dimensions: Four paradigms. In: G Burrell and G. Morgan (eds), Sociological paradigms and organizational analysis, Florence: Routledge, pp. 21-37.

Burt, R. S., 1992. Structural holes: The structure of social capital competition, Cambridge, MA: Harvard University Press.

Burt, R. S., 2009. Structural holes: The social structure of competition, Cambridge, MA: Harvard University Press.

Carrington, P. J., Scott, J. and Wasserman, S., 2005. Models and methods in social network analysis, Cambridge: Cambridge University Press.

Chesbrough, H., 2003. The logic of open innovation: managing intellectual property, California Management Review, 45(3), pp. 33-58.

Coleman, J. S., 1988. Social capital in the creation of human capital, American Journal of Sociology, pp. 95-120.

Coleman, J. S., Katz, E. and Menzel, H., 1966. Medical innovation: A diffusion study, Indianapolis: Bobbs-Merrill.

Cook, K. S. and Whitmeyer, J. M., 1992. Two approaches to social structure: Exchange theory and network analysis, Annual Review of Sociology, pp. 109-127.

Emerson, R. M., 1976. Social exchange theory, Annual Review of Sociology, pp. 335-362.

Enkel, E., Gassmann, O. and Chesbrough, H., 2009. Open R\&D and open innovation: exploring the phenomenon, $R \& D$ Management, 39(4), pp. 311-316.

Etzkowitz, H., 2003. Research groups as 'quasi-firms': the invention of the entrepreneurial university, Research Policy, 32(1), pp. 109-121.

Fleming, L. and Frenken, K., 2007. The evolution of inventor networks in the Silicon Valley and Boston regions, Advances in Complex Systems, 10(1), pp. 53-71.

Freeman, L., 2004. The development of social network analysis, A study in the sociology of science. Vancouver: Empirical Press.

Freeman, L., 2011. The development of social network analysis-with an emphasis on recent events, In J. Scott and P. Carrington (Eds). The SAGE handbook of social network analysis, Thousand Oaks, CA: Sage, pp. 26-54.

Geisler, E., 2003. Benchmarking inter-organisational technology cooperation: the link between infrastructure and sustained performance, International Journal of Technology Management, 25(8), pp. 675.

Gilsing, V., Nooteboom, B., Vanhaverbeke, W., Duysters, G. and van den Oord, A., 2008. Network embeddedness and the exploration of novel technologies: Technological distance, betweenness centrality and density, Research Policy, 37(10), pp. 1717-1731.

Granovetter, M. S., 1973. The strength of weak ties, American Journal of Sociology, pp. 1360-1380.

Granovetter, M., 1985. Economic action and social structure: the problem of embeddedness, American Journal of Sociology, 91, pp. 481-510.

Granovetter, M., 1992. Problems of explanation in economic sociology, Networks and organizations: Structure, form, and action, 25(1), pp. 56. 
Greer, C. R. and Lei, D., 2012. Collaborative innovation with customers: a review of the literature and suggestions for future research, International Journal of Management Reviews, 14(1), pp. 63-84.

Gulati, R., 1995. Does familiarity breed trust? The implications of repeated ties for contractual choice in alliances, Academy of Management Journal, 38(1), pp. 85-112.

Gulati, R., 1998. Alliances and networks, Strategic Management Journal, 19(4), pp. 293-317.

Hall, J. and Hofer, C. W., 1993. Venture capitalists' decision criteria in new venture evaluation, Journal of Business Venturing, 8(1), pp. 25-42.

Herz, A., Peters, L. and Truschkat, I., 2014. How to do qualitative structural analysis: The qualitative interpretation of network maps and narrative interviews. Qualitative Social Research 16(1), Art.9.

Hite, J. M., 2005. Evolutionary processes and paths of relationally embedded network ties in emerging entrepreneurial firms, Entrepreneurship Theory and Practice, (29)1, pp. 113-144.

Homans, G. C., 1964. Bringing men back in, American Sociological Review, pp. 809-818.

Kilduff, M., Mehra, A. and Dunn, M. B., 2011. From blue sky research to problem solving: A philosophy of science theory of new knowledge production, Academy of Management Review, (36)2, pp. 297-317.

Kirschner, P. A., Hendricks, M., Paas, F., Wopereis, I. and Cordewener, B., 2004. Determinants for failure and success of innovation projects: The road to sustainable educational innovation, Association for Educational Communications and Technology.[online] Available at: <https://eric.ed.gov/?redir=http\%3a\%2f\%2fwww.aect.org> [Accessed March 2020].

Krippner, G., Granovetter, M., Block, F., Biggart, N., Beamish, T., Hsing, Y., Hart, G., Arrighi, G., Mendell, M. and Hall, J., 2004. Polanyi symposium: a conversation on embeddedness, Socio-Economic Review, 2(1), pp. 109-135.

Larson, A. and Starr, J. A., 1993. A network model of organization formation, Entrepreneurship: Theory and Practice, 17(2), pp. 5-16.

Lyall, C., Meagher, L. and Bruce, A., 2015. A rose by any other name? Transdisciplinarity in the context of UK research policy, Futures, 65(1), pp. 150-162.

Martens, M. L., Jennings, J. E. and Jennings, P. D., 2007. Do the stories they tell get them the money they need? The role of entrepreneurial narratives in resource acquisition, Academy of Management Journal, 50(5), pp. 1107-1132.

Marwell, G. and Oliver, P., 1993. The critical mass in collective action, Cambridge: Cambridge University Press.

Maughan, D., Balenson, D., Lindqvist, U. and Tudor, Z., 2013. Crossing the" Valley of Death": Transitioning cybersecurity research into practice, Security \& Privacy, IEEE, 11(2), pp. 14-23.

McGrath, H. and O'Toole, T., 2014. A cross-cultural comparison of the network capability development of entrepreneurial firms, Industrial Marketing Management, 43(6), pp. 897-910.

Mehlman, S. K., Uribe-Saucedo, S., Taylor, R. P., Slowinski, G., Carreras, E. and Arena, C., 2010. Better practices for managing intellectual assets in collaborations, Research-Technology Management, 53(1), pp. 55-66.

Mejias, U., 2005. Re-approaching nearness: Online communication and its place in Praxis, First Monday, 10(3).

Melese, T., Lin, S. M., Chang, J. L. and Cohen, N. H., 2009. Open innovation networks between academia and industry: an imperative for breakthrough therapies, Nature Medicine, 15(5), pp. 502-507.

Miles, M. B. and Huberman, A. M., 1994. Qualitative data analysis: An expanded sourcebook. $2^{\text {nd }}$ Ed. London: Sage.

Monge, P. R., Fulk, J., Kalman, M. E., Flanagin, A. J., Parnassa, C. and Rumsey, S., 1998. Production of collective action in alliance-based interorganizational communication and information systems, Organization Science, 9(3), pp. 411-433.

Moreno, J. L. and Jennings, H. H., 1934. Who shall survive?, Washington DC; Nervous and Mental Disease Publishing Co.

Myers, M. D., 1997. Qualitative research in information systems, Management Information Systems Quarterly, 21(2), pp. 241-242.

Nahapiet, J. and Ghoshal, S., 1998. Social capital, intellectual capital, and the organizational advantage, Academy of Management Review, 23(2), pp. 242-266.

Neves, P. and Caetano, A., 2006, Social exchange processes in organizational change: The roles of trust and control, Journal of Change Management, 6(4), pp. 351-364.

Newman, M., Barabasi, A.L. and Watts, D. J., 2006. The structure and dynamics of networks, Washington DC: Princeton University Press.

Owen-Smith, J. and Powell, W. W., 2004. Knowledge networks as channels and conduits: The effects of spillovers in the Boston biotechnology community, Organization Science, 15(1), pp. 5-21.

Perkmann, M., Fini, R., Ross, J.-M., Salter, A., Silvestri, C. and Tartari, V., 2015. Accounting for universities' impact: using augmented data to measure academic engagement and commercialization by academic scientists, Research Evaluation, 24(4), pp. 380-391.

Perkmann, M. and Schildt, H., 2015. Open data partnerships between firms and universities: The role of boundary organizations, Research Policy, 44(5), pp. 1133-1143.

Perkmann, M., Tartari, V., McKelvey, M., Autio, E., Broström, A., D’Este, P., Fini, R., Geuna, A., Grimaldi, R. and Hughes, A., 2013. Academic engagement and commercialisation: A review of the literature on university-industry relations, Research Policy, 42(2), pp. 423-442.

Perkmann, M. and Walsh, K., 2007. University-industry relationships and open innovation: Towards a research agenda', International Journal of Management Reviews, 9(4), pp. 259-280.

Portes, A., 2000. Social capital: Its origins and applications in modern sociology, Annual Review of Sociology, 24, pp. 1-24.

Putnam, R. D., 1993. The prosperous community: Social capital and public life, The American Prospect, 13, pp. 35-42

Putnam, R. D., 1995. Bowling alone: America's declining social capital, Journal of Democracy, 6(1), pp. 65-78. 
Rowley, T., Behrens, D. and Krackhardt, D., 2000. Redundant governance structures: An analysis of structural and relational embeddedness in the steel and semiconductor industries, Strategic Management Journal, 21(3), pp. 369-386.

Scherngell, T. and Barber, M. J., 2011. Distinct spatial characteristics of industrial and public research collaborations: evidence from the fifth EU framework programme, The Annals of Regional Science, 46(2), pp. 247-266.

Scherngell, T. and Lata, R., 2013. Towards an integrated European research area? Findings from Eigenvector spatially filtered spatial interaction models using European framework programme data, Regional Science, 92(3), pp. 555-577.

Scott, J. and Carrington, P. J., 2011. The SAGE handbook of social network analysis, London: SAGE publications.

Steier, L. and Greenwood, R., 1995. Venture capitalist relationships In the deal structuring and post-investment stages of new firm creation', Journal of Management Studies, 32(3), pp. 337-357.

Steier, L. and Greenwood, R., 2000. Entrepreneurship and the evolution of angel financial networks, Organization Studies, 21(1), pp. 163-192.

Strang, D. and Macy, M. W., 2001. Search of excellence: Fads, success stories, and adaptive emulation, American Journal of Sociology, 107(1), pp. 147-182.

Tracy, S. J., 2013. Qualitative research methods, UK: Wiley-Blackwell.

Vandenberghe, F., 2002. Reconstructing humants: a humanist critique of actant-network theory, Theory, Culture \& Society, 19(5-6), pp. 51-67.

Wanzenböck, I., Scherngell, T. and Lata, R., 2015. Embeddedness of European regions in European Union-funded research and development (R\&D) networks: A spatial econometric perspective, Regional Studies, 49(10), pp. 1685-1705.

Wasserman, S. and Faust, K., 1994. Social network analysis: Methods and applications, UK: Cambridge University Press. Wellman, B. and Berkowitz, S. D., 1988. Social structures: A network approach, NY: Cambridge University Press.

Wenger, E., 2010. Communities of practice and social learning systems: the career of a concept. In: Blackmore C. (eds) Social Learning Systems and Communities of Practice. London: Springer, pp. 179-198

Wenger, E., Trayner, B. and de Laat, M., 2011. Promoting and assessing value creation in communities and networks: A conceptual framework, Rapport 18, Ruud de Moor Centrum Open University, The Netherlands:

Williamson, O. E., 1979. Transaction-cost economics: the governance of contractual relations, Journal of Law and Economics, pp. 233-261.

Yin, R. K., 2003. Case study research design and methods, Applied Social Research Methods Series, $3^{\text {rd }}$ Ed, Thousand Oaks, CA: Sage. 